search indicated $98 \%$ of women who came in and asked for the medication obtained it.

"In terms of identifying women's need for it, I think women do a pretty good job of it themselves," she says.

The Canadian Pharmacy Association acknowledges that even if women took levonorgestrel and didn't need it, it wouldn't cause them any harm.

The National Association of Pharmacy Regulatory Authorities arrived at its recommendation after a scientific advisory committee reviewed levonorgestrel and decided it met the evidence-based criteria for a Schedule III medication: it was safe, users could self-diagnose their condition, and the labelling and instructions were clear.

The drug, which prevents the release of an egg or prevents implantation of a fertilized egg within 72 hours of unprotected intercourse, will not affect an implanted egg or an established pregnancy. If taken within 24 hours of unprotected intercourse, it is $95 \%$ effective at preventing pregnancy.

"In the opinion of our expert committee, the safety profile of this is such that Schedule III was appropriate," says Dunsdon.

But the Canadian Pharmacy Association believes the decision should have been based on "social and other nonevidence-based aspects of drug scheduling," not just the safety of the molecule, says Cooper.

"We felt there was pretty strong evidence to show the value of the consultation with the pharmacist, but there is no evidence in terms of Schedule III improving outcomes for women."

The Canadian Pharmacy Association had asked the National Association of Pharmacy Regulatory Authorities to delay its decision about levonorgestrel until after it convened a task force to consider whether its scheduling decisions should be based on more than just science.

"We feel that the scheduling factors are too narrow, and dated, to consider all the patient care issues with emergency contraception. As such, we request that the National Association of Pharmacy Regulatory Authorities delay a decision until after the Task Force reports back, as it is important that such decisions are both evidence-based AND socially responsible," Cooper wrote in a May I4, 2008, letter to Dunsdon, a copy of which $C M A J$ obtained.

Although the National Association of Pharmacy Regulatory Authorities agreed to convene a task force, which is to report back on scheduling criteria by Nov. 2, 2008, it refused to delay the decision about levonorgestrel. "We didn't want to contaminate the process for Plan B," says Dunsdon. "The Plan B decision has been made based on current, evidence-based science."

Norway, the Netherlands, Sweden and India all dispense levonorgestrel over the counter without prescriptions. — Laura Eggertson, Ottawa, Ont.

DOI:Io.I503/cmaj.080809

\section{Canadian Nurses}

\section{Association celebrates}

\section{centennial}

W hen a devastating earthquake heaved the Indian Ocean into a tsunami that killed or injured up to 500000 people on Dec. 26, 2004, Indonesia was hit harder than any other country. The island nation, home to more than 230 million residents, lost an estimated I68 ooo people.

The Canadian Nurses Association contacted the Indonesian National Nurses Association within 24 hours, offering financial, organizational and material support. The 2 nursing bodies had a pre-existing affiliation, which allowed for direct, easy communication. Association President Marlene Smadu says the relationship was a key factor in helping the Indonesian nurses to organize relief efforts, and accounts for their receptiveness to Canadian help.

The aid effort in Indonesia is indicative of the scope of the Canadian Nurses Association's reach. The Association, which celebrates its centennial this spring, is now the largest nursing body in Canada and world-renowned for its education, regulation and advocacy work.
Smadu calls the Association the "voice of registered nurses of Canada in promoting high-quality health and nursing care." It gives nurses international reach, inspiring many countries, like Indonesia, to turn their ears northwest for advice. It certifies nurses in various specialties and even delves into politics, turning nurses into activists and lobbyists who advocate for harm reduction and prevention-centered medicine as key components of high-quality, publicly funded, egalitarian health care.

Among topics addressed at its 2007 spring conference were demanding continued federal support for InSite, Vancouver's controversial supervised injection site for illegal drug users; working with environmental lobbyists to increase research into, and public awareness of, the environmental determinants of health; and campaigning for provincial governments to put money into a national program for the HPV vaccine Gardasil.

The association formed in 1908, the fourth national nursing body to join the International Council of Nurses. Originally called the Canadian National Association of Trained Nurses, it was made up of $\mathrm{I} 6$ organized nursing groups, but this number grew to 28 within 3 years. By 1924, the organizational structure had changed to a

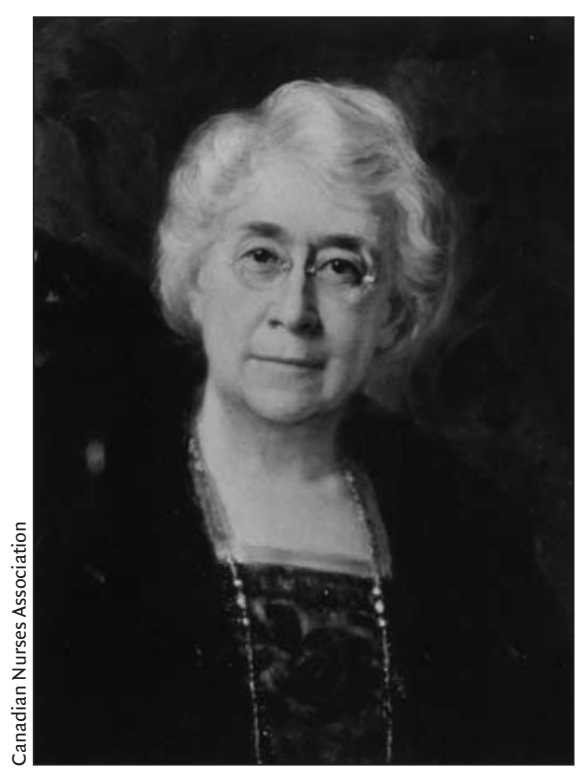

Mary Agnes Snively, the first president of the Canadian Nurses Association. 
9-body system of provincial organizations.

This basic structure still exists today, with II provincial and territorial official member organizations - and an abundance of demographic and special-interest affiliated nursing groups - working together to reflect the vast differences in nursing practice across Canada.

Since its humble beginning, focus has veered from the labour rights of nurses towards their regulation. The association is responsible for education and registration of nurses in 8 provinces (all except Ontario and Quebec) and all 3 territories.

Certification programs exist in 17 career disciplines, including cardiovascular, gerontology and neuroscience.

Algonquin College nursing professor Debra Clendinneng, certified in perioperative nursing, speaks highly of the certification program. "It's important to be a member and to promote certification ... It gives some credibility across the country and shows [certified nurses] are current in their industry."

Baccalaureate training is increasingly the norm for Canadian nurses, but few boast master's or doctorate degrees. In fact, in 2005, nurses with doctorates represented only $0.1 \%$ of all registered Canadian nurses - essentially unchanged since I989, even though the first nursing doctorate program began in I99I.

The recruitment of new nurses and the need for more nurses trained at higher levels are major public issues. Clendinneng says a very young cohort is about to replace the huge number of nurses approaching retirement. The average age of a nurse in 2005 was 45, and Canadians in their 30 s aren't highly represented in the profession. The age gap will result in a young nursing population within the next decade or so, according to a 2004 report compiled by the Canadian Association of Schools of Nursing. "One thing I really feel is that we have to get people, especially young people, excited about health care opportunities," says Clendinneng.

As managing editor of Canadian Nurse, the association's affiliated

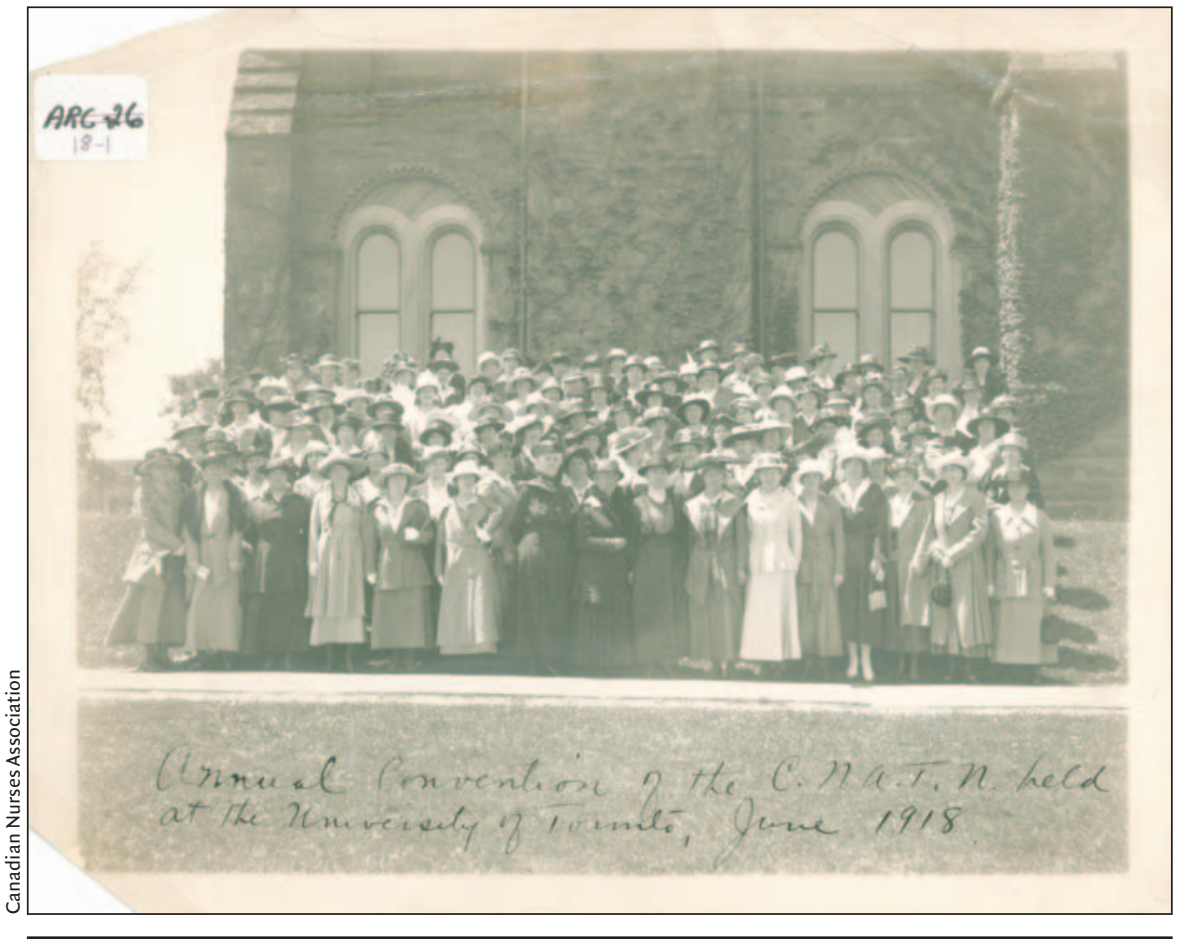

Delegates to the annual convention of the Canadian National Association of Trained Nurses (the predecessor of the Canadian Nurses Association) held at the University of Toronto in June 1918.

journal, Lisa Brazeau is conscious of the changing image of nursing. Brazeau believes the editorial focus of her journal has grown increasingly worldly to not only reflect the association's international interests, but also to keep its own nurses informed. "It's essential that all health care professionals have a bigger purview than their own world," she explains. Nurses must be able to "understand the world, either to learn from it, or to see where they can help."

Judith Oulton, former executive director of the association, has a unique perspective on how the Canadian nursing profession is viewed internationally. Now the Executive Director of the International Council of Nurses, Oulton views the Canadian Nurses Association as an organization to be emulated. "Canada is a country that I use as a model for interdisciplinary collaboration," she says. "[The Association is] very effective in maintaining strong connections, keeping the voice of nursing together between different special interest groups. They have a good history of working on an interdisciplinary basis as well, so that you see policy being developed and advocacy being done across the disciplines."

An organization's centennial is not just a time for reflection, but also a time to look forward. With the Health Canada-funded study "Vision 2020" one of the centennial's 3 major themes (along with a celebration of the past and a look at the environment's role in public health), Smadu sees nurses playing a bigger part in health practice. "Vision 2020" anticipates shorter wait times, a move away from hospitals as primary care institutions and a widespread use of telehealth services.

Another important role of the association, says Clendinneng, is to fight to ensure that health care remains public. "We have to be vigilant to make sure that that happens, that there is full public access, and I think nurses are good at that. Nursing groups have a really holistic view of the health care system. Historically, we've represented the public and marginalized patients within the health care system." Nicole Chatelain, Ottawa, Ont.

DOI:I0.I503/cmaj.080705 